\title{
MACROMOLECULE REJECTION WITH COMPRESSIBLE AND INCOMPRESSIBLE CAKE LAYER FORMED IN CROSSFLOW MICROFILTRATION
}

\author{
TAKAHIRO KAWAKATSU*, SHIN-ICHI NAKAO AND \\ SHOJI KIMURA \\ Department of Chemical Engineering, University of Tokyo, \\ Bunkyo-ku, Hongo 7-3-1, Tokyo 113
}

\begin{abstract}
Key Words: Membrane Separation, Crossflow Microfiltration, Cake Compression, Blocking Resistance, Saccharomyces cerevisiae, Polymethyl Methacrylate, Macromolecule Rejection, Bovine Serum Albumin, Dextran, Dynamic Membrane
\end{abstract}

\begin{abstract}
In crossflow microfiltration (CMF) of a suspension of Saccharomyces cerevisiae, a dense layer called a " dynamic membrane" was formed with elastic compression at the interface of the membrane surface and the cake layer, and was found to reject bovine serum albumin (BSA) and Dextran T70 (T70). This macromolecule rejection corresponded to the blocking resistance $\left(R_{b}\right)$, and was dependent on the actual surface pore size $\left(d_{m}\right)$, the particle size in suspension $\left(d_{p}\right)$ and the particle compressibility. With $S$. cerevisiae, when $d_{m}$ at $0.5 \mu \mathrm{m}$ was about one-tenth of $d_{p}(2-5 \mu \mathrm{m})$, the T70 rejection rate increased to $80 \%$ even if $d_{m}$ was large compared to the size of T70. The membrane surface was observed with scanning electron microscopy and it was confirmed that a dense layer with compressed cells and biopolymers surrounding the cell was formed on the surface. On the other hand, the T70 rejection was not observed with the cake layer of polymethyl methacrylate particles $\left(d_{p}\right.$ : $0.8 \mu \mathrm{m}$ ) because the particle was incompressible and no dense layer was formed.
\end{abstract}

\section{Introduction}

Crossflow microfiltration has been studied as an effective separation method in bio-industry. For continuous production of an enzyme, Cheng et al. ${ }^{1)}$ used a membrane bioreactor system with Bacillus caldolyticus which produced an extracellular enzyme, $\alpha$-amylase. In our previous work ${ }^{3)}$, a membrane bioreactor system was also used for the production of $\beta$-galactosidase (molecular weight (MW): 130,000, extracellular enzyme) with Penicillium multicolor. In CMF of the fermentation broth, $20-60 \%$ of $\beta$-galactosidase was rejected even if microfiltration (MF) membranes were used. The enzyme rejection with MF membranes was considered to be due to cake compression and dense layer formation on the membrane surface.

The increase in rejection of the macromolecule (e.g., enzyme) has been a serious problem in CMF. Kroner et $a l .{ }^{5)}$ filtered fermentation broth for the harvesting of cells and separation of enzymes from cells or cell debris. Enzymes, especially intracellular enzymes which had to be separated from disrupted cells, were partially rejected by the cake layers. When the disrupted cells of Candida boidinii were concentrated to 25-52 vol.\% from 4-8 vol.\%, the yield of formate dehydrogenase ranged within 34-62\% because of the enzyme rejection. Le and Atkinson ${ }^{6)}$ separated intracellular enzymes from cell debris by CMF. Membrane pore size

* Received March 2, 1993. Correspondence concerning this article should be addressed to T. Kawakatsu, National Food Research Institute, Kannondai 2-1-2, Tsukuba, Ibaraki 305. affected the decline of flux and enzyme permeability. In three types of Asypor membranes with nominal pore sizes of $0.2,0.45$ and $0.6 \mu \mathrm{m}$, decrease in flux with 0.45 $\mu \mathrm{m}$ was the lowest in filtration of Erwinia carotovora for $4 \mathrm{~h}$. The membrane was asymmetric and both the tight side and the open (loose) side of the membrane surface could be used against the feed. With the tight side against the feed, the enzyme permeability decreased rapidly compared to the open side, probably owing to the formation of a secondary membrane (a dense layer) on the membrane surface. Le and Gollan ${ }^{7)}$ considered the effects of membrane material with hydrophilic $\mathrm{MF}$ membranes $(1.2 \mu \mathrm{m})$ with galactopyranose copolymer coating. The permeability of $\alpha$-amylase (MW: 50,000 ) in a Bacillus broth and malate dehydrogenase (MW: 70,000 ) in a yeast broth could be kept at $100 \%$ for $30-60$ min in dead-end filtration, when the operation pressure and the cell concentration were $137.88 \mathrm{kPa}$ and about 1 $\mathrm{kg} / \mathrm{m}^{3}$, respectively. However, at a high initial cell concentration, $10 \mathrm{~kg} / \mathrm{m}^{3}$, the permeability was lower than 10 $\%$. The flux also decreased drastically in this case. On the other hand, addition of 1\% BSA to the broth (cell concentration: $1 \mathrm{~kg} / \mathrm{m}^{3}$ ) had little effect on either the permeability or the flux; that is, the amount of soluble protein had little effect. There was room for further consideration of the effects of the hydrophilic membranes; the membrane pore size was constant and relatively large $(1.2 \mu \mathrm{m})$, the experiment time was short (30 or $60 \mathrm{~min}$ ) and concentration polarization might reduce 
the observed rejection in dead-end filtration. However, it is interesting that the cell concentration had an effect on enzyme permeability but soluble protein did not. The presence of the cells on the membrane surface must be a significant factor in the permeability and the flux. The first objective of this study is to investigate the macromolecule (BSA, T70) permeability in CMF of suspensions of compressible microorganism cells ( $S$. cerevisiae, i.e., yeast) or incompressible polymethyl methacrylate (PMMA) particles with the surface pore size as a parameter. The second objective is to observe the cake layer, the appearance of the cells and, if any, something of a dense layer on the membrane surface after CMF with photographs by scanning electron microscopy (SEM photographs).

\section{Theoretical Background}

\subsection{Compression of cake layer}

Generally, cake layers of microorganism cells are known to be compressible. Nakanishi et al. ${ }^{9)}$ measured the specific resistance of the cake layer with several kinds of microorganisms and latex particles. The specific resistance of microorganisms showed a dependence on the operating pressure, but that of latex particles showed little dependence. Cells of $S$. cerevisiae are generally known to be rigid in comparison to other microorganisms, but are compressible compared to inorganic solids. In addition, extracellular macromolecules (polysaccharides, lipoproteins, and so on) surrounding the cell are supposed to be deformed by pressure. Fermentation residues such as molasses are also considered to have large effects on the filtration flux. Tanaka et al. ${ }^{10)}$ showed that when the yeast was cultivated with glucose, the flux was higher than with molasses.

Cake layers of hard particles, which are individually incompressible, are often compressible. Tiller et $a l .{ }^{11)}$ reviewed cake compression mechanisms and stated that incompressible particles form compressible cakes. In their theory, cake compression occurs by two mechanisms: the principal one is consolidation by degradation of particle aggregates with movement of particles into open spaces (nonelastic mechanism). In the second mechanism, particles at a high pressure may deform or be crushed, and the deformation depends on the elastic properties of the particle (elastic mechanism). Therefore, it is concluded that elastic compression mainly occurs with compressible particles such as microorganism cells, and that only nonelastic compression occurs with incompressible particles, and it is assumed that the cake layer with microorganism cells shows strong rejection of macromolecules compared to that with incompressible particles.

Gatenholm $e t$ al. ${ }^{2)}$ compared the performances of a MF membrane $(0.2 \mu \mathrm{m})$ and an ultrafiltration (UF) membrane (MW cutoff: 100,000) during cell harvesting of $\mathrm{E}$. coli and observed the membrane after filtration with SEM and TEM (transmission electron microscopy). At
30 min, the flux with the UF membrane was somewhat higher than that with the MF membrane, although the pure water flux of the MF membrane was about 80 times higher. The cake layer on the MF membrane was at least $5 \mu \mathrm{m}$ thick, with very densely packed cells, and that on the UF membrane was less than $0.5 \mu \mathrm{m}$ thick, with cell debris and small fibrils. The interpretation of the flux difference was that the cells could not adhere to the UF membrane because the membrane surface was too smooth for the microorganism cells and biopolymers surrounding the cell. There is room for another interpretation: that the mass of the cake layer in MF was much larger than that in UF since it was controlled by the hydrodynamic balance of the flux and the crossflow velocity, and that the flux decline in MF must also have been larger with the growth of the specific resistance as the cells became densely packed (elastic compression).

\subsection{Effect of membrane surface pore size}

In our previous work ${ }^{4}$, the actual surface pore sizes of several MF membranes were measured from SEM photographs, those of UF membranes were estimated by calculation from molecular weight cutoff values, and the effects of the actual average surface pore size of a membrane $\left(d_{m}\right)$ and the particle size $\left(d_{p}\right)$ on the steady-state flux (SSF) in CMF of the PMMA or the yeast suspension were studied. The hydrodynamic resistances were then divided into three series resistances: membrane resistance $\left(R_{m}\right)$, cake resistance $\left(R_{c}\right)$ and blocking resistance $\left(R_{b}\right)$. For the yeast suspension, when $d_{m}$ was about one-tenth of $d_{p}, R_{b}$ reached a local maximum and the SSF was at a minimum, since the yeast cells surrounded by biopolymers or residues were easily compressed and they accelerated the pore blocking. On the other hand, when $d_{m}$ was nearly equal to $d_{p}$, the compression of particles was weak; thus $R_{b}$ was not very large and SSF remained relatively high. For instance, using the loose side of the FM22 membrane (LS, $d_{m}: 2.5$ $\mu \mathrm{m})$ against the feed, SSF was about twice as large as the tight side (TS, $d_{m}: 0.5 \mu \mathrm{m}$ ), mainly owing to $R_{b}$, although there was little difference in the cake mass on LS and TS. When $d_{m}$ was much smaller than $d_{p}$, SSF was rather high, probably for the same reason described with reference to the results of Gatenholm et al. ${ }^{2)}$ (1. Compression of cake layer).

The result that the blocking resistance $R_{b}$ drastically increases when $d_{m}$ is one-tenth of $d_{p}$ suggests the formation of a dense layer at the interface between the membrane surface and the cake layer. Therefore, it is assumed that the increase in $R_{b}$ enables MF membranes to reject macromolecules.

\section{Materials}

MF and UF membranes used in this study were asymmetric flat membranes made of cellulose triacetate and polysulfone, respectively. The MF membrane, FM22, was purchased from Fuji Photo Film Co., Ltd.; its $d_{m}$ of TS was $0.5 \mu \mathrm{m}$ and that of LS was $2.5 \mu \mathrm{m}$. The UF 
Table 1. Operating conditions

\begin{tabular}{lccc}
\hline Suspension & $\begin{array}{c}\text { Macromolecule } \\
\text {-water (control) }\end{array}$ & $\begin{array}{c}\text { PMMA } \\
\text {-water }\end{array}$ & $\begin{array}{c}\text { S. cerevisiae } \\
-0.86 \% \text { NaCl sol. }\end{array}$ \\
\hline Operating pressure $[\mathrm{kPa}]$ & 60 & 60 & 50 \\
Feed velocity $\left[\mathrm{m} \cdot \mathrm{s}^{-1}\right]$ & 1.6 & 1.6 & 1.1 \\
Temperature $\left[{ }^{\circ} \mathrm{C}\right]$ & 27 & 27 & 25 \\
Concentration $\left[\mathrm{kg} \cdot \mathrm{m}^{-3}\right]$ & 0.1 & 3 & 5 \\
\hline
\end{tabular}

membranes, UF300PS and UF1OOOPS, were purchased from Tosoh Co.. The $d_{m}$ of UF300PS was $0.03 \mu \mathrm{m}$ and that of UFIOOOPS was $0.05 \mu \mathrm{m}$.

As a compressible model particle, $S$. cerevisiae (active dry yeast for baking), for which $d_{p}$ ranged from 2 to $5 \mu \mathrm{m}$, was purchased from Oriental Yeast Industry Co., Ltd. and was suspended in $0.86 \% \mathrm{NaCl}$ solution (physiological saline). The $\mathrm{pH}$ of the suspension was 5-7. The latex particles MP1401, made of polymethyl methacrylate (PMMA), were purchased from Soken Chemical and Engineering Co., Ltd. The PMMA particle was an incompressible spherical particle of which $d_{p}$ was 0.8 $\mu \mathrm{m}$, and it had a narrow size distribution, a slight negative charge and a high dispersibility. The PMMA particles were suspended in water and the suspension was pretreated for $30 \mathrm{~min}$ by ultrasonic dispersion to minimize particle aggregation.

Bovine serum albumin (BSA, MW: 69,000) was purchased from Sigma Chemical Co. and Dextran T70 (T70, MW: 70,000) from Pharmacia LKB Biotechnology. T70 was considered to have properties of low adsorption and little aggregation.

\section{Methods}

\subsection{Apparatus and CMF condition}

The membrane module used was a thin-channel crossflow cell (UFP-2, Mitsui Petrochemical Industries, Ltd.) having a channel width of $7 \times 10^{-2} \mathrm{~m}$, length of 17 $\times 10^{-2} \mathrm{~m}$ and height of $1.5 \times 10^{-3} \mathrm{~m}$. The effective membrane area of the cell was $1.04 \times 10^{-2} \mathrm{~m}^{2}$. A magnetic pump (MD-1OOR-z, Iwaki Co., Ltd.) was used to supply the operating pressure and the feed circulation. Both concentrate and permeate were returned to the feed tank in order to maintain constant bulk concentration. Operating pressures, feed velocities, feed temperature and suspension concentration (based on dry weight) are given in Table 1.

\subsection{Measurement of macromolecule rejection}

In this work, the macromolecules (BSA, T70) were treated as tracer materials to investigate the effects of cake formation time on cake layer condition and dense layer formation. Therefore, to reduce the interaction of the macromolecules and the suspended particles, the macromolecules were added not in the initial feed suspension but in the feed after the cake layer had been built. The volume of the additional macromolecule solution was small enough to have no effect on the feed particle concentration, and after the highly concentrated
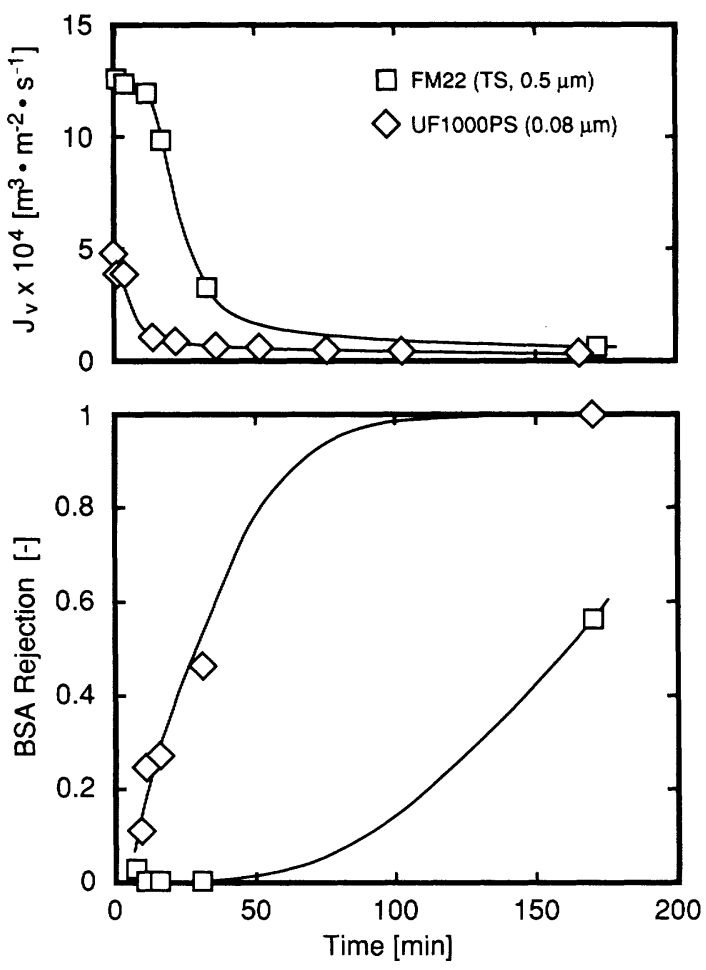

Fig. 1 Time course of flux and of BSA rejection during CMF of 100 ppm BSA solution

solution was added, the macromolecule concentration became about $0.1 \mathrm{~kg} / \mathrm{m}^{3}$ in the feed suspension. The feed suspension and the filtration permeate were sampled before and after the addition (sampling time based on the addition: $-1,1,3,5,10 \mathrm{~min}$, and so on). The collected suspension was centrifuged at $1500 \mathrm{G}$ for $30 \mathrm{~min}$ and the supernatant was used as the sample solution. The macromolecule concentration was measured from the difference in total organic carbon in the sample solutions before and after the macromolecule addition, and finally the rejection rate was calculated from the ratio in the macromolecule concentration in the feed and permeate. For rejection at various operation times, new filtration experiments were performed at each measurement.

\subsection{SEM photograph}

By SEM photographs we observed the appearance of cells on the membrane which had been dried using the critical-point drying method. Before double fixation with $2 \%$ glutaraldehyde solution (overnight) and $1 \%$ Osmic acid solution (1 hour), the membranes were washed gently to remove excess cake immediately after $\mathrm{CMF}$. The $\mathrm{pH}$ of the fixation solutions was adjusted to 7.3 with $0.1 \mathrm{M}$ phosphate buffer. After the fixation, the membranes were rinsed with the buffer, then with ethanol solutions of which the ethanol concentration was raised gradually to $100 \%$, and finally with $100 \%$ isoamyl acetate, to be dried using the critical point drying method. 

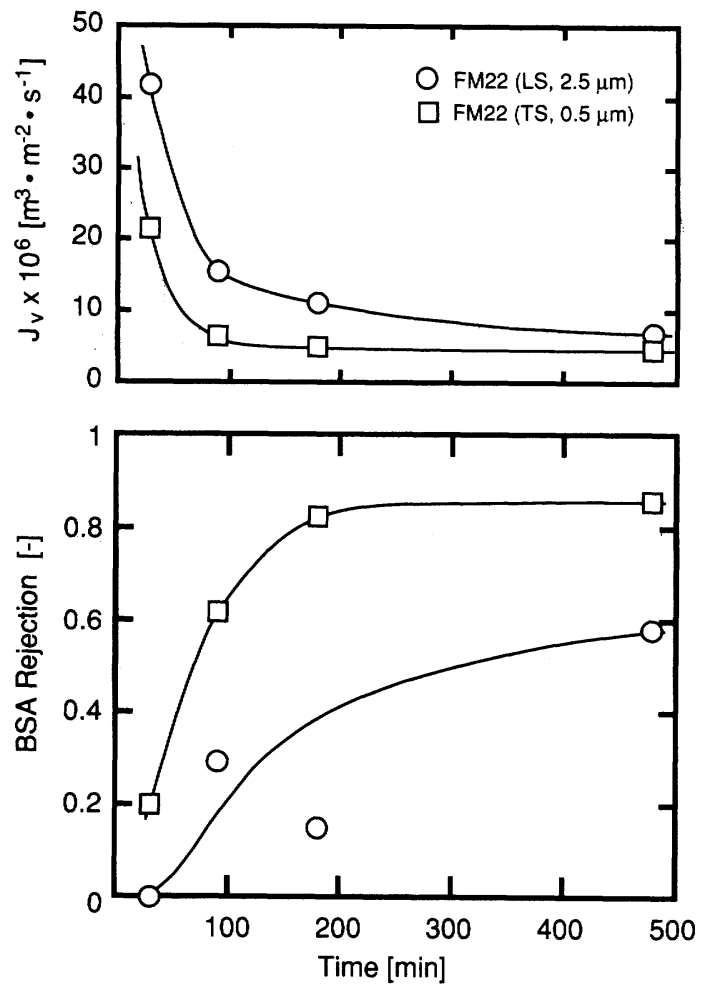

Fig. 2 Effect of yeast cake formation time on flux and on BSA rejection

\section{Results and Discussion}

\subsection{Rejection of Bovine serum albumin}

Figure 1 shows the time course of the flux and the BSA rejection during CMF of $0.1 \mathrm{~kg} / \mathrm{m}^{3}$ BSA solution. Although the BSA molecule was about $0.01 \mu \mathrm{m}$ and small compared to the membrane pore sizes, the BSA molecule was rejected even if FM22 (TS, $0.5 \mu \mathrm{m}$ ) was used. Since rejection was not detected in the early periods, the aggregation of BSA molecules might have occurred during filtration and the aggregated BSA prevented further penetration of other BSA molecules. A similar result was observed in the study by Gatenholm $e t$ $a .^{2)}$, and with $0.22 \mathrm{~mm}$ of Durapore MF membrane the BSA rejection was about 7-9\% at $85 \mathrm{~min}$ in filtration of $0.1 \%$ BSA solution. The effect of the yeast cake formation time (filtration time) on the flux and the BSA rejection is demonstrated in Fig. 2. The flux with FM22 (LS) was about twice as much as that with FM22 (TS), mainly owing to the $R_{b}$ difference. Using FM22 (LS), the rejection was about $60 \%$. Not only with FM22 (LS) but also with FM22 (TS), the increasing profile of the rejection corresponded to that of $R_{b}$ (Fig. $\left.18^{4}\right)$ ), and the rejection rate reached $80 \%$. With the use of FM22 (TS), though PMMA particles were considered to be inelastic, the BSA rejection with PMMA cake (cake formation time: $600 \mathrm{~min}$ ) was $90 \%$, probably owing to BSA aggregation and some interaction of the BSA molecules with the PMMA particles.

Matsumoto et al. ${ }^{8)}$ studied the property in CMF of the model suspension with a mixture of microorganisms
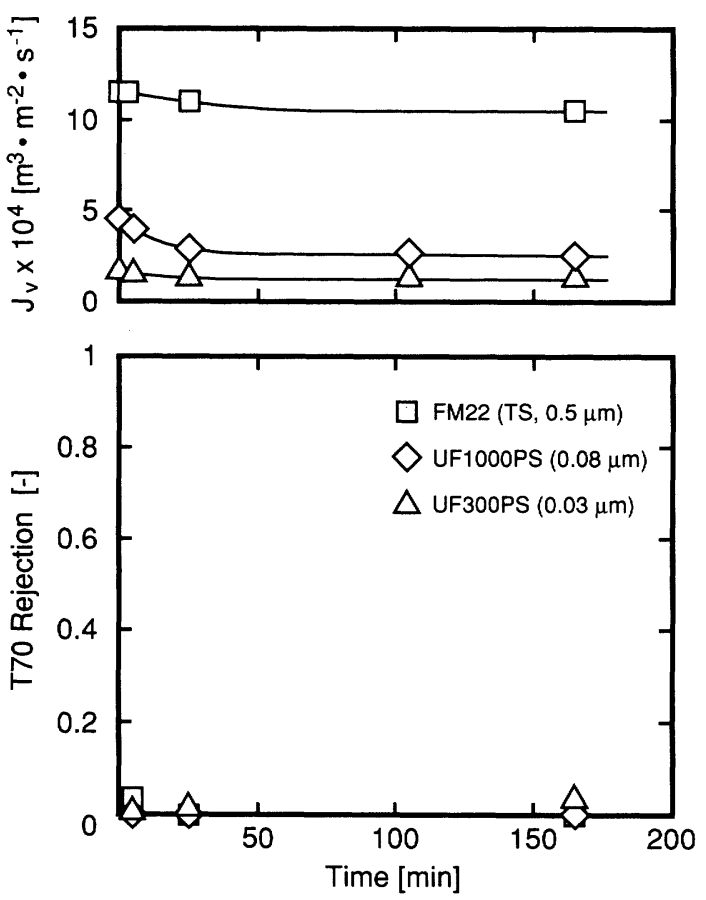

Fig. 3 Time course of flux and of T70 rejection during CMF of $100 \mathrm{ppm}$ T70 solution

(or PMMA particle) and BSA. The rejection of BSA was $30-40 \%$ under the following conditions: operating pressure of $40 \mathrm{kPa}$, feed velocity of $1 \mathrm{~m} / \mathrm{s}$, yeast concentration of $10 \mathrm{~kg} / \mathrm{m}^{3}$, BSA concentration of $1 \mathrm{~kg} / \mathrm{m}^{3}$ and filtration time of $480 \mathrm{~min}$. They used LS of FM22 $\left(d_{m}\right.$ $2.5 \mu \mathrm{m}$ ), and profiles of the rejection was similar to those in our results. The BSA rejection rate rose at higher operating pressure, at lower feed velocity and with higher yeast concentration, for the same filtration time. However, at the steady state, rejection was independent of the yeast concentration. On the other hand, with PMMA particles (MP1401, $d_{m}: 0.8 \mu \mathrm{m}$ ), the rejection was $40 \%$ at the steady state, though its rate of increase was much slower than that with the microorganism cells. One explanation for the BSA rejection of the PMMA cake layer, in which elastic compression did not arise, may be that BSA molecules have a tendency to be adsorbed to the particle surface and to aggregate easily, and the aggregated BSA prevented further penetration by other BSA molecules.

\subsection{Rejection of dextran T70}

The time course of the flux and of the T70 rejection during CMF of $0.1 \mathrm{~kg} / \mathrm{m}^{3} \mathrm{~T} 70$ solution is shown in Fig. 3. Although the molecular size of T70 was almost the same as that of BSA, T70 molecules had properties of low adsorption and little aggregation. Consequently, the flux decline was very slight and T70 rejection did not occur in the operation period with any membrane. The time course of the flux and of the rejection of T70 added at the steady state in CMF is shown in Fig. 4. With the yeast cakes, the $T 70$ rejection property was almost the same as that of the BSA. FM22 (LS): $60 \%$ (BSA), $40 \%$ (T70); FM22 (TS): $80 \%$ (BSA), $70 \%$ (T70). The results 


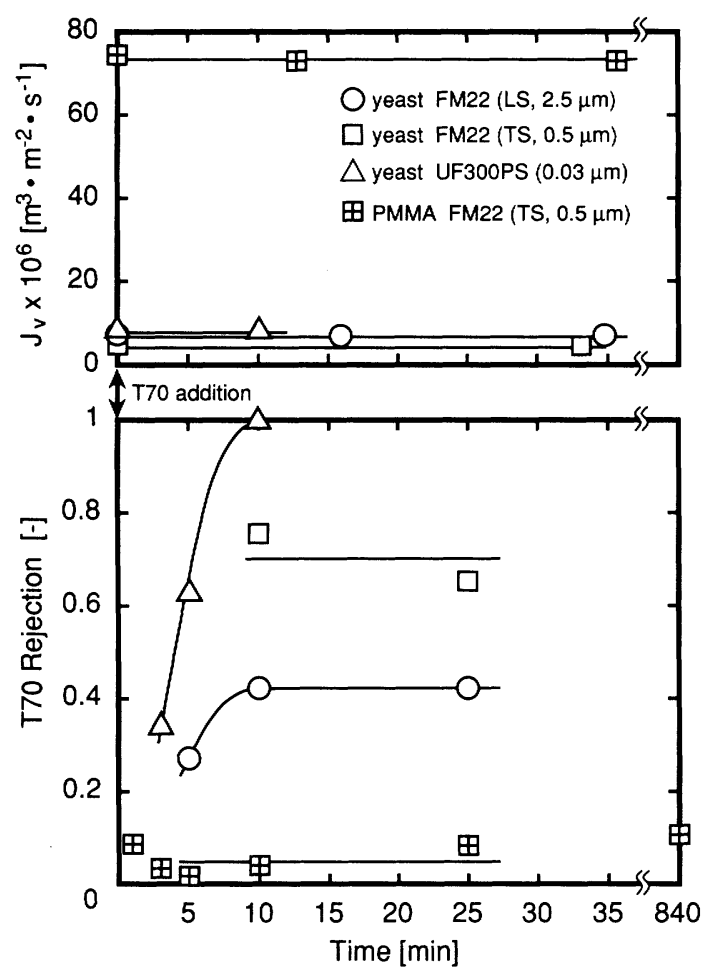

Fig. 4 Time course of flux and of rejection of T70 added at steady state in CMF (Cake formation time: $480 \mathrm{~min}$ with yeast, 600 min with PMMA)

are valid considering the molecular size of BSA and T70. With the use of UF300PS $(0.03 \mu \mathrm{m})$, the rejection rate increased drastically to reach $100 \%$. One interpretation is that there might be interaction among the T70 molecule, the membrane pore and the dense layer on the membrane surface since $d_{m}$ was only three times the size of T70. The rejection with the PMMA cake was, by contrast, kept at a very low level (nearly equal to zero) for a long time, $840 \mathrm{~min}$. This is evidence for the absence of a dense layer, and the PMMA particle was then confirmed to be inelastic. Figure 5 demonstrates the effect of yeast cake formation time on the flux and on T70 rejection. The increasing profile of the rejection also corresponded with that of $R_{b}$ (Fig. 18 $\left.{ }^{4}\right)$.

\subsection{SEM photographs}

Figures 6, 7 and 8 show the SEM photographs after CMF of the yeast suspension with FM22 (LS), FM22 (TS) and UF300PS, respectively. The filtration period was $480 \mathrm{~min}$. For photographs with the same magnification, the washing strength of the cake layer before fixation was slightly changed in accordance with the target of observation, i.e. the cake layer or the dense layer on the membrane surface. For FM22 (LS), something fouled on the membrane surface, but the presence of a dense layer such as aggregate with compressed cells was not observed. This suggests that the macromolecule rejection of $40 \%$ was attributable to the cake layer as a whole. For FM22 (TS) and UF300PS, in contrast. yeast cells were connected by biopolymers or some unknown material, and deformation of the cells was also observed (in the
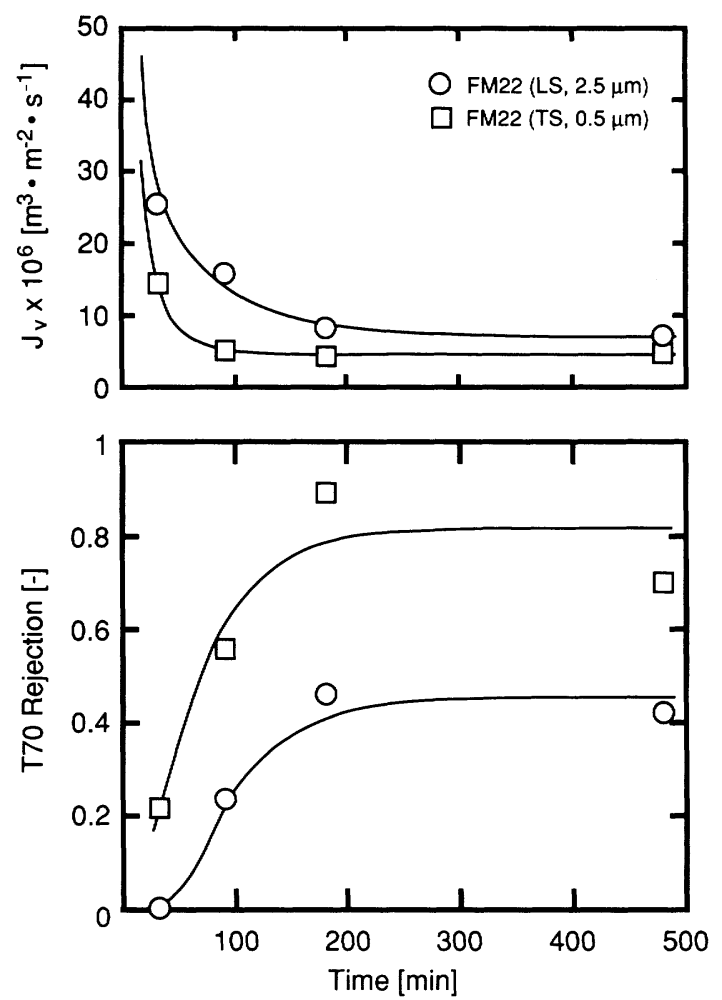

Fig. 5 Effect of yeast cake formation time on flux and on T70 rejection

right top and the center bottom photographs in Fig. 7, and in the center one in Fig. 8). Except for extracellular biopolymers and fermentation residues, the materials surrounding the cells are supposed to be cell debris and intracellular components produced by cell lysis, which occurs due to elastic compression on the membrane surface, though the effect of the shear stress with feed circulation is not negligible. If we consider that the macromolecule rejection rate increased to $70 \%$ or more due to the dense layer, it can be stated that the presence of the cells on the membrane surface is a significant factor in macromolecule rejection.

SEM photographs after CMF of the PMMA suspension with FM22 (TS) are shown in Fig. 9. The filtration time was $600 \mathrm{~min}$. There were no fouling materials such as biopolymers except for the particles themselves, and their deformation was observed to be slight. Some particles seemed to be deformed, but they existed from the start.

\section{Conclusions}

In CMF of a suspension of compressible particles (yeast cells), a dense layer was formed with elastic compression on the membrane surface, which simultaneously increased the blocking resistance and the macromolecule rejection. The macromolecule rejection and the blocking resistance were dependent on $d_{m}, d_{p}$ and the particle compressibility. When $d_{m}$ was about one-tenth of $d_{p}(2-5 \mu \mathrm{m})$, the rejection rate of macromol- 


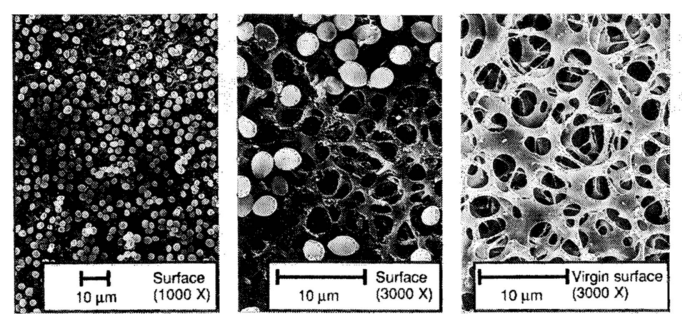

Fig. 6 SEM photographs after CMF of yeast suspension with FM22 (LS, $d_{m}: 2.5 \mu \mathrm{m}$ ) (Filtration time: $480 \mathrm{~min}$ )
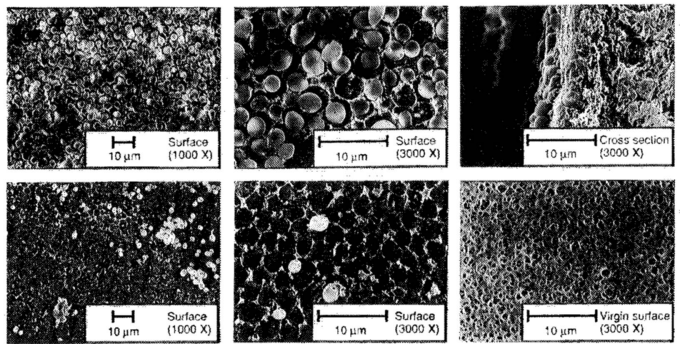

Fig. 7 SEM photographs after CMF of yeast suspension with FM22 (TS, $d_{m}: 0.5 \mu \mathrm{m}$ ) (Filtration time: $480 \mathrm{~min}$ )

ecules increased drastically to $80 \%$ even if $d_{m}$ was large compared to the size of macromolecules. Rejection of T70 was not observed with the PMMA cake layer on the same membrane because the particle was incompressible and no dense layer was formed. Since BSA molecules have a tendency to be adsorbed and to aggregate easily in contrast with $\mathrm{T} 70$, the adsorbed and aggregated BSA prevented further penetration by other BSA molecules when BSA solution was merely filtered with MF membrane $\left(d_{m} 0.5 \mu \mathrm{m}\right)$. By SEM photographs it was confirmed that a dense layer made of the compressed cells and biopolymers surrounding the cell was formed on the membrane surface. However, it should be mentioned that these experimental results were obtained under limited conditions. The results may vary according to the fermentation conditions of the yeast, the operating methods and so on, as Tanaka et al. ${ }^{10)}$ suggested.

\section{Nomenclature}

$d_{m} \quad=$ actual average surface pore diameter of membrane

$[\mathrm{m}]$

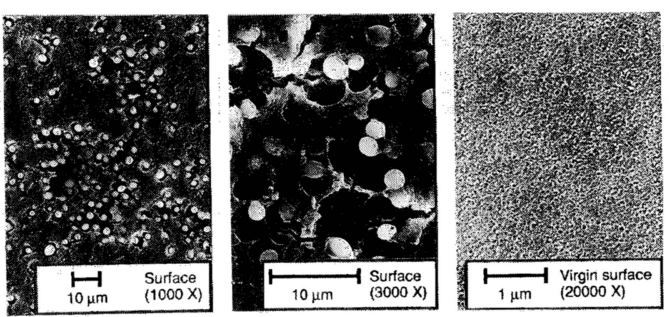

Fig. 8 SEM photographs after CMF of yeast suspension with UF300PS $\left(d_{m} 0.03 \mu \mathrm{m}\right)$ (Filtration time: $480 \mathrm{~min}$ )


Fig. 9 SEM photographs after CMF of PMMA suspension with FM22 (TS, $d_{m}: 0.5 \mu \mathrm{m}$ ) (Filtration time: $600 \mathrm{~min}$ )

$d_{p} \quad=$ particle diameter $\quad[\mathrm{m}]$

$J_{v} \quad=$ flux

$R_{b} \quad=$ blocking resistance $\quad\left[\mathrm{m}^{-1}\right]$

$R_{c} \quad=$ cake resistance $\quad\left[\mathrm{m}^{-1}\right]$

$R_{m} \quad=$ membrane resistance $\quad\left[\mathrm{m}^{-1}\right]$

Literature Cited

1) Cheng, C., Yabe, I. and Toda, K.: Hakkokogaku, 68, 367 (1990)

2) Gatenholm, P., Fell, C.J. and Fane, A.G.: Desalination, 70, 363 (1988)

3) Kawakatsu, T., Miwa, T., Matsumoto, Y., Nakao, S. and Kimura, S.: J. Ferment. Bioeng., 75, 126 (1993)

4) Kawakatsu, T., Nakao, S. and Kimura, S.: J. Membrane Sci., 81, 173 (1993)

5) Kroner, K.H., Schütte, H., Hustedt, H. and Kula, M.R.: Process Biochem., 19, 67 (1984)

6) Le, M.S. and Atkinson, T.: Process Biochem., 20, 26 (1985)

7) Le, M.S. and Gollan, K.L.: J. Membrane Sci., 40, 231(1989)

8) Matsumoto, Y., Totsuka, Y., Miwa, T., Nakao, S. and Kimura, S.: Kagaku Kogaku Ronbunshu, 18, 677 (1992)

9) Nakanishi, K., Tadokoro, T. and Matsuno, R.: Chem. Eng. Comm., 62,187 (1987)

10) Tanaka, T., R. Kamimura, K. Itoh, K. Nakanishi and R. Matsuno: Biotechnol. Bioeng., 41, 617 (1993)

11) Tiller, F.M., Yeh, C. and Leu, W.F.: Sep. Sci. Technol., 22,1037 (1987) 